\title{
Jung, Parapsychology, and the Near-Death Experience: Toward a Transpersonal Paradigm
}

\author{
Michael Grosso \\ Department of Philosophy \\ Jersey City State College
}

\begin{abstract}
This study examines the near-death experience (NDE) in the light of the Jungian theory of archetypes. Features of the prototypical NDE are matched against features of archetypes. The near-death process is discussed in terms of the concept of the individuation of the Self. NDEs are looked at as evidence for the activation of a unique archetype associated with rebirth experience, designated the archetype of death and enlightenment (ADE). The general function of the ADE is outlined, and evidence for psychic manifestations of it is reviewed: mystical phenomena, dreams, mythology, mystery and initiation rites, psychedelic experiences, and UFO "revelations." Possible objections to the theory are considered along with some broad cultural and religious implications.
\end{abstract}

\section{INTRODUCTION}

The following is an attempt to examine the near-death experience (NDE) in the light of Carl Jung's theory of archetypes. I also wish to stress the need to integrate parapsychology as central for putting the NDE in adequate perspective. The NDE is an interdisciplinary field of study; it touches on neurology, psychiatry, religion, philosophy, anthropology, mythology, psychology, and parapsychology. The theory of archetypes may provide the type of conceptual framework we can use, one that is sufficiently comprehensive and flexible.

The main object here will be to articulate a perspective, model, or paradigm - a general way of thinking about NDEs. Given the limitations of space, I can only offer a sketch, though the archetype hypothesis normally demands detailed textual study. For instance, my remarks in this paper on the Eleusinian Mysteries are a condensation of a large mass of hitherto unpublished material. Further, it will not be possible to deal in detail with rival theories. In a previous paper (Grosso, 1981b) I attempted a critique of some possible explanations of NDEs; while in no way suggesting that the issues raised in that paper are resolved, I wish in the present study to concentrate on a constructive and synthetic statement.

Let me then begin by summarizing why I think the Jungian per- 
spective may be of service in our study of the near-death experience.

(1) It respects the intrinsic experience of the near-death experiencer, especially the sense of tremendous meaningfulness, of having encountered a supremely important reality. It is true that not all NDEs are tremendously meaningful; moreover, as several writers have correctly observed, the NDE may be a complex phenomenon with multicausal origins. Nevertheless, the impact on those who have the core transcendental experience usually carries with it a coherent and uniformly notable sense of intense meaningfulness. It is to this core of transcendental meaningfulness that the present theory addresses itself in a nondestructive way. By contrast, other theories tend to devalue and derealize the intrinsic experience of the neardeath encounter by categorizing it as hallucinatory, illusory, or epiphenomenal.

(2) It is compatible with what Greyson (1982) called a "normal neurophysiological adaptive response." For instance, evidence for temporal-limbic hyperactivity or endorphin release would be, as we shall see, compatible with the hypothesis that NDEs activate archetypal psychic contents.

(3) The present model complies with another suggestion cited by Greyson (1981): the need for a psychodynamic interpretation of near-death phenomena. Thus the Jungian approach stresses the psychodynamic function of compensation. However, there is a crucial addition: Jungian psychodynamics postulates a transpersonal level of psychic reality, the level of the "collective" unconscious.

(4) The model, unlike most psychodynamic theories, is compatible with the paranormal elements frequently reported in near-death research. This fourth point follows from the third. The transpersonal level of psychic reality is a level that ostensibly operates independently of time and space, which is another way of describing paranormal functioning.

(5) The model makes falsifiable predictions - one in particular for which there is already an impressive, though inexcusably neglected, body of evidence.

(6) NDEs may themselves be taken as empirical evidence in support of the hypothesis of archetypes, those universal patterns of imagery, affect, and behavioral dispositions that Jungian depth psychologists call attention to. Thus strengthening the support for Jung's theory, we may be encouraged to use the theory to deepen our understanding of the NDE.

(7) The theory of archetypes enables us to view NDEs as evidence for a pervasive psychic function associated with dying. This perva- 
sive and recurrent pattern of primordial images, affects, and behavioral dispositions I call the archetype of death and enlightenment (ADE). It is this ADE that in my previous paper (1981b) I dubbed the archetype of a healthy death. It was by going beyond the NDE setting into the realm of certain psychedelic experiences, UFOs, mystery rites, mysticism, dreams, and so forth - that I was led to the idea of an underlying psychic structure capable of functioning independently of the near-death setting. In coining the expression ADE, then, I am not just relabeling the NDE but naming a new theoretical construct, one that I believe identifies a transpersonal psychic structure associated with human death and dying.

Nor does it seem too far-fetched to suppose that human life has evolved in such a way that it provides for a healthy death - a process grounded in "mechanisms" derived from the depths of the human organism. Should the genetic "intelligence" that controls our integration into life be so indifferent to our disintegration out of it? Moreover, it is hardly surprising that the code - or archetype - of this transformation we call dying is not the product of the conscious mind or the personal unconscious mind but of Mind-at-Large, of what Jung called the Objective Psyche.

The significance of such a code or archetype for medical science, and for a general theory of humankind, would be considerable. For it is possible, as Jung argued, that "modern man" - that solitary, anxious, driven being, spiritually uprooted and traditionless - has lost touch with the healing symbols and energies of the deep psyche that help us to cope with death and dying. One of the main purposes of this paper is to draw attention to the possible existence of such a transpersonal healing force.

In this paper then I shall concentrate on the level of functioning Jung postulated as deeper than the personal unconscious. This is not to slight the importance of the personal unconscious. That would be absurd, since we are all more or less imprisoned by the dynamics of the personal unconscious. However, for the moment I will be focusing on gleams cast by NDEs that suggest it may be possible to transcend the cave of the personal unconscious and come into the sun of the Whole Self.

\section{THE ARCHETYPAL NATURE OF NEAR-DEATH EXPERIENCES}

I shall not deal here with the problem of the origin and the ontological status of the archetypes but will confine myself to remarks on their phenomenological character and their function in relation to NDEs. 


\section{Archetypes and Typical Situations}

Jung wrote: "There are as many archetypes as there are typical situations in life ... [They represent] merely the possibility of a certain type of perception and action" (1971, p. 48). Dying is one of the typical situations of life; it would therefore be surprising if there were no archetype related to the dying process.

A systematic clarification of Jung's concept of the archetype is beyond the scope of this paper. Suffice it to say here that the archetypes derive from the transpersonal or collective unconscious. The archetype is a primordial mental structure inexplicable in terms of personal experience or the personal unconscious. But one of the most striking features of the NDE is the transpersonal nature of its imagery. Researchers have generally been impressed by the uniformity of the NDE. Typical features of the NDE occur independently of personal variables such as age, sex, education, religion, and culture.

Although the basic structure of the NDE does not appear to be conditioned by personal variables, there are variations in detail of content. This, however, squares with Jung's distinction between the archetype as nonperceptible, a form without content, and the archetype as perceptible, a mediated item of personal experience. The former is a theoretical construct based upon the latter, empirical data.

\section{Fluidity and Ineffability of the Archetype}

The archetypes, according to Jung, "appear under an almost infinite variety of aspects" $(1971$, p. 81$)$. "A kind of fluid interpretation belongs to the very nature of the archetype," he said, and further, "no archetype can be reduced to a simple formula . . . but they change their shape continually" (1971, p. 179). The fluid and indefinable nature of the archetypes - also called primordial images or dominants of the collective unconscious - accounts in part for the frequently reported ineffability of NDEs. Archetypes represent the point of interaction between personal experience and the collective experience of humankind; they are charged with a surplus of meaning that overflows the boundary of personal time and space. This fact may account for their ineffability. Ordinary human language functions to describe ordinary and familiar events in time and space. The task of communicating the plenitude of meaning in the encounter with archetypes demands the heightened powers of expression of a Dante or a Blake. It is no wonder that the ordinary person returns from the NDE stammering with hyperboles. 
An Archetype of Transformation

Jung spoke of a category of archetype that, in addition to personified imagery (the Wise Old Man, the Anima, the Trickster, etc.), consists of "typical situations, places, ways and means ..." (1971, p. 38). These he called archetypes of transformation. One might think of the NDE as exhibiting the central archetype of transformation, since death, symbolically, and in fact, is the most radical type of transformation. The term "archetype," in conjunction with the NDE, embraces a constellation of motifs or recurrent patterns; in the NDE we find personifications - guides, light-beings, religious and mythical figures - as well as situations, ways, and places such as coming to a border, seeing marvelous landscapes, passing through a tunnel, moving from darkness to light, and so on.

\section{How Do We Know Archetypes Exist?}

The archetypes of the collective unconscious reveal their existence through several spontaneous sources: dreams, "active imagination," trance fantasies, psychotic delusions, and dreams of early childhood. Jung spoke of a diminishment of ordinary waking consciousness as a condition for their appearance. Again it is not surprising that the radical diminishment of ordinary consciousness in the near-death state should give rise to archetypal motifs. In fact, the most drastic diminishment of ordinary consciousness would seem to occur in cases of clinical death. Being near death must be regarded as an optimal state for activating contents of the collective unconscious.

Jung's arguments for the collective or transpersonal nature of these contents varied. Typically, the argument took the following form. A subject $-\mathrm{a}$ child or uneducated person - has a dream. The dream displays imagery and motifs not traceable to the dreamer's conscious experience but parallel to imagery and motifs found in mythology, alchemy, mystery rites of antiquity, or other obscure but world-old sources. The dream is thought therefore to originate from the collective strata of the human mind.

There are alternatives to the collective-mind hypothesis for explaining such cases. The most obvious is cryptomnesia, or unconscious memory. In some cases a telepathic influence might be invoked, although some might find this harder to swallow than the archetypes themselves. Nevertheless, there is an impressive body of evidence for the existence of extrasensory perception. Certainly the evidence for ESP is stronger experimentally than it is for the arche- 
types. (On the other hand, archetypes might function in a way that presupposes telepathy or other forms of psi.)

In any case, the evidence is fairly strong that near-death imagery is not traceable to the personal experience of individuals; as such, near-death imagery may be viewed as evidence for a transpersonal, collective realm of mind. We know very little about this ego-transcendent order of mind. What we do know we have had to glean from the speculations of philosophers like Plato and Kant, the visions of seers like Swedenborg or George (AE) Russell, or the ecstasies of a Padre Pio. What we don't know is if this shore we are glimpsing is a mirage conjured by the collective, anxious ego or if it is something more solid, more substantial. Jungian studies, parapsychology, and near-death research begin to suggest that there may be a degree of "solidity" unsuspected by orthodox science.

The Autonomy of the Archetypes

Archetypes behave autonomously; they "come upon us like fate" (Jung, 1971, p. 30). This tallies with the near-death experience. For instance, religious beliefs and expectations per se do not influence the frequency of NDEs, which is what we would expect if they derived from the collective unconscious. Osis and Haraldsson (1977) cited the case of an avowed atheist who had a deathbed vision of Christ. According to the theory of archetypes, dominants of the collective unconscious are activated to compensate for the onesidedness of the conscious mind. According to this theory, atheism would be an extreme state of one-sidedness, a state of alienation from the great powers of the unconscious. The vision of Christ might very well occur in the case of the atheist, as a compensatory response for a psyche in extremis.

On the other hand, most NDErs who encounter a vision of Christ are Christians. Yet even here there is support for the autonomous nature of the near-death imagery. The literature is full of anecdotes about dying persons who had visions that conflicted with their conventional expectations. For instance, they expected to see angels with wings but instead saw transfigured beings in human form (Grosso, 1981b). Further, we have little information about the depth of religious belief in NDErs. Weak, merely nominal Christians would need to compensate for their spiritual poverty as much perhaps as atheists. In either case, atheist or faithful Christian, dying is an extreme situation; either one is liable to fall back upon the resources of the collective storehouse. Archetypes, like NDEs, are psychic 
reflexes. They just happen, in spite of, and even because of, the limitations of the personal ego. Archetypes and NDEs are harbingers of the Self that is greater than the personal ego.

According to Jung (1959; see also Edinger, 1974), Christ is the dominant symbol of the archetype of the Self in the Western world. I shall return to the theme of the Self; for now we note how frequently in Western studies NDErs "see" Christ. Often all they "see" is a great light - a form without content - but most of the time they project the Christ-content. In the cross-cultural studies of Osis and Haraldsson (1977), Hindu religious figures were "seen" or projected. In Becker's (1981) study of NDEs and Pure Land Buddhism, cases were reported of deathbed visions of the Buddha. The basic function of the near-death archetype appears to be constant; the contents projected vary depending on culture and other personal variables.

The autonomy of the death-related phenomena is also evident from the following remark of Osis and Haraldsson: "It seems that apparitions show.a purpose of their own, contradicting the intentions of the patient" $(1977$, p. 87). In short, the apparitions are not projections of the personal psyche. They exhibit a purpose of their own: to "take away" the dying person to another world. Emotions of peace and serenity correlated significantly with these otherworldly messengers with a take-away purpose. Transcendental emotions, however, did not correlate with thisworldly visions or hallucinations of the living.

This was construed by Osis and Haraldsson as evidence for the survival hypothesis. If for the moment we bracket the survival problem, we can at least note that these findings figure in terms of the theory of archetypes. "Otherworldly messengers" would be equivalent to "messengers" from the "other world" of the collective unconscious. Such messengers, or archetypes, proceeding from the "wholly other" strata of the collective mind would indeed have the most profound impact on subjects. In some cases the impact would be negative; in fact Osis and Haraldsson (1977) reported cases in which dying subjects resisted with terror messengers with a "take-away" purpose. These "no-consent" cases, moreover, argue against Freudian reductionism, which sees near-death phenomena as essentially wish-fulfilling effects based on a denial of death.

The Numinous and the Will to Live

Research has shown that "encounters with ostensible messengers 
from the other world seemed to be so gratifying that the value of this life was easily outweighed" (Osis and Haraldsson, 1977, p. 185). This is a prominent feature of NDEs as well as deathbed visions. The higher near-death states were so appealing that revival was met with reluctance and regret. Jung himself had a remarkable neardeath experience and wrote: "I felt violent resistance to my doctor because he had brought me back to life" (1961, p. 293). Jung said it took him more than three weeks to make up his mind to live again. He regretted having to return to this "gray world with its boxes." The other world he glimpsed was fuller, not fragmented by time or bound by space:

Although my belief in the world returned to me, I have never since entirely freed myself of the impression that this life is a segment of existence which is enacted in a three-dimensional boxlike universe especially set up for it (Jung, 1961, p. 295).

How can we account for this seeming reversal of the biological instinct to live? The most obvious explanation is the plain fact of having to return to a sick body racked with pain. The value of life in this case would be reduced in contrast to the painless near-death hallucination. However, judging from Jung's and other near-death reports, the reluctance to return is based on something intrinsically valuable, namely, having touched upon the deepest reservoirs of meaning and psychic energy. The archetypes, saturated with numinous power, fascinate and enthrall. Jung (1961), for instance, saw Zeus and Hera consummate the mystic marriage, among other marvels. The contemplation of such awe-inspiring images and the cosmic feelings associated with them are enough to weaken the ordinary will to live.

\section{The Feeling of Immortality}

Studies by Ring (1980), Sabom (1982), and others have shown an impressive array of positive aftereffects of NDEs. Chief among them was a dramatic reduction of the fear of death. The reduction of this particular fear makes sense in terms of the theory of archetypes. The fear of death would decline with the experience of the feeling of immortality, but for Jung this feeling is associated with the non-temporal and non-spatial nature of the collective unconscious. "The feeling of immortality," Jung wrote, "has its origin in a peculiar feeling of extension in space and time" (1971, p. 142). NDEs may induce this feeling of extension (along with the reduction of death anxiety) in at least two ways. 
First, NDEs may activate the archetypes. Archetypes represent points of entry into a collective psychic world not bound by ordinary time and space. Vivid archetypal experience would thus enhance the feeling of being extended beyond space and time. Jung understood ancient deification rites in this light; as group techniques for projecting the archetypes - Dionysos, Persephone, Isis, etc. Utilizing hypnotic, right-hemisphere languages, sensory overload, psychoactive drugs, trance-dancing, etc., celebrants were led into altered states, which triggered exalted visionary experiences. By means of these visions celebrants believed they were temporarily united with the gods, hence, with the roots of immortality. This feeling of immortality or sense of deification reported in ancient mystery rites (Grosso, 1981a) should not, of course, be confused with propositional knowledge; it is more like the noetic sense of the mystical experience, an intuitive sense of knowing that is state-dependent.

A second way NDEs might induce feelings of being extended beyond space and time is through the out-of-body experience. A common feature of near-death states is having the experience of being out of one's body. Out-of-body experiences (OBEs) may be subjective or veridical. In the former, the subject just has a feeling of being dislocated from his or her body. In veridical cases, there may be evidence that the subject was in fact observing events at a point in space separate from the location of his or her body. The most convincing evidence for veridical OBEs, OBEs with genuine psi components in NDEs, is found in Sabom (1982). In either case, the feeling of being extended at least in space is part of the experience.

In veridical OBEs, information is obtained paranormally about events occurring in physical space. However, the Jungian frame of reference is neither incompatible with nor inhospitable to the data of parapsychology. Near-death research, in fact, would be a fertile area for exploring the relations between parapsychology and the theory of archetypes. One hint from Jung will suffice. "The factor," he wrote, "which favors the occurrence of parapsychological events is the presence of an active archetype" (1976, p. 511). For Jung the presence of an active archetype implied a condition for overcoming the limitations of time and space, and thus a condition that is psi-conducive.

\section{The Bipolarity of Archetypes and NDEs}

Collective psychic phenomena also involve extensions in time. This brings us to another feature of archetypes that helps us to understand near-death phenomena. The Jungian analyst Jacobi referred 
to the bipolar nature of the living archetypes: "Like a Janus head, it [the archetype] is turned both 'forwards' and 'backwards,' integrating into a meaningful whole all the possibilities of that which has been and of that which is still to come" (1974, p. 75). NDEs afford ample evidence of the bipolar aspect of the archetype.

First, consider the phenomenon of panoramic memory or flashback. Near-death experiencers often report the sense of grasping the past events of their lives as a meaningful whole; the events of the past are experienced as spatialized into an all-encompassing present. On the other hand, there have been reports of what Ring (1982) called flashforwards. In some cases, these indicated trends of future events; in a few cases, they appeared to contain more specific elements of genuine precognition. There have also been reports (Ring, 1982; Audette, 1982) best described as prophetic visions of a collective nature. The death-inspired visionary seemed to catch glimpses of forces bearing on the collective future of mankind. This extension in time we may call the horizontal axis of the archetype.

There is also a vertical, qualitative axis. Archetypes are bipolar in that they stretch backwards and forwards in time, and in a second sense in that they have a bright and high side as well as a dark and low. Jung wrote: "Just as all archetypes have a positive, favorable, bright side that points upwards, so also they have one that points downwards, partly negative and unfavorable, partly chthonic ..." (1958, p. 190). The bright, favorable side of the NDE is well known, but there have also been dark, chthonic encounters in the near-death state, less frequently reported (Rawlings, 1978; Lindley, Bryan, and Conley, 1981). It is conceivable that these dark, so-called hellish, visions have been reported less because, understandably, they were repressed. Or even if they were not entirely repressed, those who had this type of vision might have held back from reporting it simply because they wanted to forget or because their experiences did not fit into the widely publicized format. In any case, the content (devils, lakes of fire and brimstone, etc.) of these frightening visions has been patently archetypal in character. As a result of this ignored, hellish aspect, the NDE more clearly resembles the mythical and religious accounts of the afterlife. (See, for instance, Jung's (1957) psychological commentary on The Tibetan Book of the Dead.) The clearer this resemblance, the clearer the case is for the archetypal nature of the NDE. 


\section{Metanoia and the NDE}

Reduction of the fear of death, which I have discussed, is only part of a larger pattern of positive aftereffects. In cases where this larger pattern is fully displayed, it is hard to avoid the impression that one is observing a type of religious conversion. We might even describe the full-fledged NDE as a natural conversion process. The person converted experiences a pervasive change of value and outlook (Flynn, 1982). The word for this transformation of mind in the New Testament is metanoia, and it might be useful to speak of the metanoid component of the NDE. St. Paul's experience on the road to Damascus, which has some of the classic features of the NDE, is a historically dramatic case in point. This raises the interesting possibility of the origin of religion - St. Paul was one of the founders of Christianity - being linked to near-death experience.

The focal point of this metanoid component of the NDE is sometimes expressed in terms of cosmic, unconditional love. In the words of one experiencer: "I would describe this love I encountered in dying as 'unconditional.' It was so powerful, so complete, so forgiving, so all-knowing, so encompassing, it transcended all forms of earthly love ..." (Atwater, 1981, p. 6). The author described how her normal emotional relations were disturbed by her NDE; her customary attachments had become an obstacle to further growth. A new, transpersonal dynamic of love was set in motion. The NDE here seems to release a new force that disrupts the routines of average everydayness. One is inclined to see in such descriptions the daimonic power of Eros rather than the ego struggling to defend itself against extinction.

However, there are problems with the release of this new force. A failure to integrate it may lead in Jungian terms to an "inflation" of the ego. Some NDErs become almost obsessed with their experiences and complain of a new kind of loneliness, an inability to adjust to a world that falls short of the perfection they glimpsed. Inflation runs over into its opposite, deflation. Unfortunately, the liberating and the dangerous effects of the archetypes are inseparable. Given the increasing numbers of NDErs, usually in a medical setting, the problem of how to handle near-death aftereffects, positive and negative, is a challenge to the medical profession and - even more so - to the deep structure of the medical "paradigm." One of the main purposes of this paper is to recommend that the teachings of Jung offer a wide and flexible framework for dealing with these problems. 
But let us proceed to another point about the transforming power of near-death archetypes. The effects appear sometimes to operate indirectly on persons who hear reports of NDEs (Ring, personal communication, 1980). There are analogies for this sort of "direct transmission," "contact high," or "shaktipat" in the group dynamics of religious experience. The idea in brief is that merely by being in the presence of, or interacting personally with, individuals who have had an "enlightenment" experience, one may undergo deep spiritual changes. An odd illustration of this is the case of the cardiologist Maurice Rawlings, in which the conversion took place indirectly through the dark, hellish side of the archetype. His book, Beyond Death's Door, (1978), scarcely a scientific document, has the urgent intensity of a sermon by Jonathan Edwards - testimony to the numinous and possessing power of the archetypes. But Rawlings's was by no means typical of near-death changes in value systems; the change is usually toward a broadened spiritual outlook, not toward doctrinaire fundamentalism.

The Self and the Near-Death Archetype

The Self, or objective psyche, according to Jung, is always seen as outside, as transcendent. The near-death experiencer "sees" a transcendent light outside. Ring (1980) came by a different speculative route to a conclusion on this compatible with Jungian thought. Ring wrote that the being of light, voice, or presence is simply oneself. "It is not merely a projection of one's personality, however, but one's total self, or what in some traditions is called the higher self. In this view, the individual personality is but a split-off fragment of the total self with which it is reunited at the point of death" $(1980$, p. 240).

The extraordinary light phenomena of NDEs would then be symbolic of the higher consciousness of the total self. Jung in connection with his study of alchemy remarked, ". . . the archetypes have about them a certain effulgence or quasi-consciousness . . . and numinosity entails luminosity" (1968, p. 191). So powerful are these luminous effects, symbols and expressions of an extended consciousness, that they are difficult to integrate into the normal personality. It is therefore no surprise that experiencers often believe that the "being of light" is God. Jung commented: "We know that an archetype can break with shattering force into individual life ... It is therefore not surprising that it is called "God'." The final say on this belongs to the province of theology. The most we are entitled to affirm is that 
for the person who has had this type of experience, the outer limits of the Self appear to have been encountered. Many Westerners, of course, are likely to insist on a sharp opposition between the notions of Self and God. Yet in some traditions this distinction is rejected as ultimately illusory, as we find in the Gospel according to St. John, the Hindu doctrine of the identity of Atman and Brahman, the teachings of the Tibetan Book of the Dead, etc. Indeed, according to the latter, our task is to recognize that the Divine Light before which we stand in awe is a projection of the Self. One of the lessons of the near-death experience may be to ratify empirically this mystical doctrine of the deep identity of Self and God. Theology itself may turn to the near-death experience as a source of renewal. After all, the most exalted ideas are ultimately grounded. in some human experience.

\section{THE ARCHETYPE OF DEATH AND ENLIGHTENMENT}

Enough has been said to indicate the archetypal nature of the NDE. Let us say then that the NDE activates an archetype of the collective unconscious, a constellation of motifs that portrays a process of enlightenment, a passage toward greater consciousness of the Self. I will label this constellation of near-death-related motifs the archetype of death and enlightenment (ADE). The NDE is a dramatic and full manifestation of the ADE; however, as we shall see, other circumstances exist in which this archetype is activated. Moreover, just as every component or motif of the prototypical NDE does not appear in every near-death experience, so every component and motif of the ADE does not appear in every situation in which this archetype is in evidence. The common thread is a deathrebirth process, but biological death is only one extreme condition for activating the ADE. Psychological, spiritual, or cultural "neardeath" states may also suffice. Almost any crisis of transformation, spontaneous or artificial, individual or collective, could stir up these powerful psychic dominants.

\section{The Meaning and Function of the ADE}

If the Self is the master archetype expressing the goal or telos of the organism, namely, individuation, then we may think of the ADE as portraying the transformation process of realizing that goal. The $\mathrm{ADE}$ is a dynamic representation of the Self in process.

Analysis of near-death imagery reveals a coherent web of meanings 
central to the process of becoming a Self. To begin with, there is the abstract image of moving from darkness to light (i.e., from unconsciousness to consciousness). This is probably one of the most universal symbols. For instance, in the Bradaranyaka Upanishad we hear: "From non-being lead me to being, from darkness lead me to the light, from death lead me to immortality." In the NDE the sequence is also from darkness to light. We observe the same sequence in many creation myths: in the Rig Veda, Hesiod's Theogony, the Old Testament, and the Scandinavian Eddas. For Jews, Arabs, Germanic peoples, Celts, and many others, day begins with the evening; darkness is prior to the dawning of the light.

Another common motif of near-death imagery is passage through caves, holes, tunnels, or the like into a situation of openness. This particular motif usually indicates rebirth, passage to a new and higher plane of being. The Allegory of the Cave in Plato's Republic (Bk. 7) is a landmark in Western philosophy. In it enlightenment is pictured as an escape from imprisonment in a cave into the light of the sun. The cave motif appears again in the Myth of the True Earth in Plato's Phaedo (see Grosso, 1971). Modern philosophy has, of course, strayed from its archetypal beginnings; near-death research might help point the way back to the archetypal origins of philosophy.

The guides NDErs meet - deceased persons, other-worldly messengers, religious or mythic - are more personified manifestations of the same theme. The guides oversee the process of transition. They may do so by assisting in what Ring (1980) called the "decisional process," in which the near-death experiencer returns to this world, almost invariably with a renewed existential outlook. Whether the imagery is abstract (dark-light, tunnel-opening) or personal (guide, deceased relative, religious figure), the fundamental idea is passage from enclosure to disclosure.

The out-of-body motif is a parapsychological actualization of the same dynamic unit of meaning. Going out of the body means transcending the fundamental enclosure of embodied personal existence. The body itself is a cave, hole, or tunnel transcended in the neardeath experience; dying, like being born, means release from enclosure. One thinks here of the ancient Orphic formula soma sema (the body is a tomb). True life then calls for going out of the body. The symbolic meaning of the NDE confronts us with a Nietzschean Umwertung aller Werte, a transvaluation of all values. Dying, construed by the ego to be the ultimate disaster, signifies access to Self transformation and the highest values.

The enclosure-disclosure unit of meaning has its cognitive and 
temporal aspects. The candidate for enlightenment has his or her past disclosed in the panoramic memory; the future is also disclosed as symbol, as probable trend, or sometimes as veridical precognition. The enclosure-disclosure passage is also functionally equivalent to the passage from part, or ego, to whole, or Self. The interplay of near-death imagery confirms the central meaning or message. For instance, the ego is normally in the dark with respect to the light of the Self. Light, the symbol of consciousness, is central to the near-death experience; meetings with deceased relatives, out-of-body states, and panoramic memories are all manifestations of the "Light." They all imply extensions of consciousness, inroads to transcendence of time and space.

However, the central unifying symbol of light is not just symbolic, not just an abstraction. The light is also a literal fact, an intense, aweinspiring experience. The light is brilliant, dazzling, warm, peaceful, elating, vivid, sensuous. It is both pure and formless as well as an aspect of formed beings, whether human or "angelic," or of celestial landscapes, cities of light, and so forth. The all-pervasive character of the near-death light is crucial to the authenticity of Jung's concept of the Self. The fully individuated Self is marked by a coincidence of opposites - the abstract and the concrete, intellect and sensation. Thus, the near-death epiphany is not only abstract and symbolic, pointing to an enlarged awareness; it is also personal, embodied, sensuous, thrilling, and visceral, be it in the form of persons, otherworldly beings, or supernal landscapes. It is, in short, real. Experiencers concur on this. What they experience has a distinctive quality of being real, even we might say superreal. The superreality or special intensity of the NDE, in Jungian terms, results from it being an experience of individuation, of undividedness, of integration of conscious and unconscious, of all our mental energies. Mircea Eliade, in his study of experiences of the mystic light, wrote: "Experience of the Light signifies primarily a meeting with ultimate reality: that is why one discovers the interior Light when one becomes conscious of the Self (atman) or when one penetrates into the very essence of life and the cosmic elements, or, last of all, at one's death" (1965b, p. 43).

The meaning of archetypes is also functional, intentional, and dynamic. The function of the archetype of death and enlightenment is to compensate for the ego's one-sided conception of death. Affectively, this means overcoming the fear of death. Existentially, it implies that death promises rebirth, a change in the state of one's being. Cognitively, it signifies an expansion of consciousness. Meta- 
physically, it involves reorientation toward a universal, indestructible spiritual reality. The new mode of being heralded by the ADE may be thought of as post-mortem or as taking place on the plane of premortem existence.

While the ADE guides the ego toward a new consciousness of the Self, it rescues death from meaninglessness. This is important in an age when increasing numbers of people are succumbing to the "existential vacuum." As traditional ideas of life after death lose hold even among the religious, the archetypal NDE offers a fresh source of meaning and direction to the conscious mind, pointing backwards and forwards to structures that embody the wisdom of nature. Jung wrote:

Hence it would seem to be more in accord with the collective psyche of humanity to regard death as the fulfillment of life's meaning and as its goal in the true sense, instead of a mere meaningless cessation. Anyone who cherishes a rationalistic opinion on this score has isolated himself psychologically and stands opposed to his own basic human nature (1978, p. 409).

The idea that death is the goal of life in its truest sense - i.e., the essential condition for rebirth, for a new and higher life and mode of being - runs totally counter to the modern rationalist outlook. Nevertheless, this is the message that most clearly emerges from the near-death phenomenon, and it is consistent with the claims of the collective psyche of humanity, its religions and mythologies. Such a conception implies a Copernican revolution with respect to the prevailing modern view. It places the sun of the objective psyche at the center of spiritual reality, challenging what may be an illusion of the conscious ego: that death is a mere meaningless cessation.

\section{THE NEAR-DEATH ARCHETYPE IN LIFE}

We have now to consider another type of argument showing the archetypal nature of the NDE. If the constellation of factors associated with near-death exemplify an ADE, then similar factors need not be exclusively associated with near-death. Literal near-death would be only one possible trigger for the $\mathrm{ADE}$. Any situation threatening ego death, major life changes and transitions, might activate the healing powers of the ADE.

The nature of the crisis and the context (near-death, dreams, mystical states, etc.) would determine which factors of the archetypal constellation would come to the fore. For instance, deceased relatives are a more likely factor in a crisis of literal near-death. In nonliteral, ego-death situations the appearance of deceased relatives 
would be to no purpose. There is one quantitative study that confirms this hypothesis. Gabbard, Twemlow, and Jones (1981) found that no characteristics were exclusive to NDEs as compared to OBEs in a non-near-death context, but they did find that certain characteristics were significantly related to NDEs, such as encountering deceased relatives, etc. Gabbard, Twemlow, and Jones compared NDEs to OBEs in which there was no threat to life. This comparison is slightly odd, since out-of-body experience is usually taken as a prominent component of the near-death experience. I don't think this slight degree of circularity vitiates the validity of their study; however, the critical question they pose - do near-death experiences occur only near death? - needs to be examined in the light of better examples. A phenomenological sketch of possible areas for such a comparison might include mystical phenomena, dreams, mythology, initiation and mystery rituals, psychedelic experiences, UFO "revelations," and so forth. These by no means exhaust the spectrum of possible sources, but they will suffice for our purpose. The aim here is to make a prima facie case for the claim that near-death-related factors are evidence for a collective psychic structure not exclusive to near-death experiences. Nevertheless, I would hold that the NDE is perhaps the most dramatic and reliable source of evidence for the reality of what I have chosen to call an archetype of death and enlightenment.

\section{Mystical Phenomena}

The resemblance between NDEs and mystical phenomena has already been noted by researchers (Noyes, 1971; Noyes and Kletti, 1976). Russell Noyes wrote that the mystical consciousness "seemed not so much a distinct element of the altered state under examination (i.e., the NDE) but rather its more extreme progression" (1971, p. 25). The elements of this mystical extension cited by Noyes include transcendence of space and time, feelings of unity, loss of will, sense of truth, and intense emotion - all of which are features of archetypal experience. NDEs and mystical experience appear to be alternate routes to the same archetypal matrix of consciousness.

NDEs and some mystical experiences are spontaneous. But some mystical experiences result from artificial practice or discipline and show a connection with near-death states. One thinks, for example, of Plato's view of philosophy as the practice of death, or of yogis who put themselves in deathlike trances. Eliade, for instance, referred to medical testimony showing that "the reduction of respiration and 
cardiac contraction to a degree that is usually observed only immediately before death" $(1958$, p. 57$)$ is something yogins are able to accomplish at will. The Catholic scholar Mager said that there exists a relation between supranormal elevations of consciousness and supranormal lowering of the vital functions. Concerning the supernatural Christian ecstasy, Mager wrote:

... the physical life approaches a death-like state, the breathing is reduced, the heart and the pulse become slower, the vital warmth disappears, the limbs stiffen, the outer and inner senses are wholly bound. It is as if the soul, as in death, were separated from the body (Arbman, 1968, p. 210).

The story of the great modern Hindu mystic, Ramana Maharshi, shows the relationship between ego-death and enlightenment experience. Ramana was in perfect health when one day he became panicstricken that he was about to die. I quote his remarkable statement at length:

The shock of the fear of death drove my mind inwards and 1 said to myself mentally, without actually framing the words: 'Now death has come; what does it mean? What is it that is dying? This body dies.' And I at once dramatized the occurrence of death. I lay with my limbs stretched out stiff as though rigor mortis had set in and imitated a corpse so as to give greater reality to the enquiry. I held my breath and kept my lips tightly closed so that no sound could 'escape, so that neither the word 'I' nor any other word could be uttered. 'Well then,' I said to myself, 'this body is dead. It will be carried stiff to the burning ground and there burnt and reduced to ashes. But with the death of this body am I dead? Is the body I? It is silent and inert but I feel the full force of my personality and even the voice of the 'I' within me, apart from it. The body dies but the Spirit that transcends it cannot be touched by death. That means I am the deathless Spirit.' All this was not dull thought; it flashed through me vividly as living truth which I perceived directly, almost without thought-process. ' $I$ ' was something very real, the only real thing about my present state, and all the conscious activity connected with my body was centered on that ' $I$. ' From that moment onwards the ' $\mathrm{I}$ ' or Self focussed attention on itself by a powerful fascination. Fear of death had vanished once and for all (Osborn, 1973, p. 18).

In this unusual case a psychodrama imitating death gave rise to an experience of mystical illumination. I might also note here that the encounter with the Self was facilitated by Ramana's not resisting the idea of his imminent death; he let go, gave up, in a way that is reminiscent of some types of NDE. This act of surrender, enhanced by an inhibition of normal respiration, apparently triggered the experience of the Self. The process of voluntary or involuntary ego-surrender is what evokes the latent powers of the Self or Total Psyche, according to Jung. 


\section{Dreams 1}

The dream is a crucial source of our hypothesized ADE, since the dream is the most immediate inroad to the collective unconscious. Jung observed in patients drawing near the end of their lives dreams with rebirth symbolism. The following is from my collection of neardeath dreams.

Less than a year prior to his death, an elderly man dreamt he was climbing a mountain. There were three levels to the ascent, and at each level the light and surrounding landscape became brighter, more peaceful, and more beautiful. At the top he experienced the utmost of bliss, but some men there, who were digging a hole in the ground, told him to go back down by following the path he came by. He complied with the request because he realized he had to return something, a jacket he was holding, the first his wife had given him almost fifty years ago.

This resembles an NDE in several ways: the association of light, bliss, and beauty with death (symbolized by the digging); reaching a border; and having to turn back because of a link (the jacket) with a loved one. The archetypal quality of climbing a tri-layered mountain is obvious.

Let me give another, curiously similar, example. In this case a chronically ill woman "gave up," wanted to die, and dreamt she went on a journey:

Upon reaching a mountain I began to climb. As I climbed higher and higher, the great "cloud" that covered everything began to dissolve, and patches of sunshine began to shine through. At last I reached the top and flung myself onto the level ground, whereupon the "sun" suddenly broke out all around and permeated my entire being with healing, love, and total splendor. It was an indescribable experience of such stark truth that the memory seemed to have engrained itself in my deepest being. I felt the way a person should feel. It was more real than anything I have ever known (Skaar, 1982, p. 14).

The author went on to describe herself as if flying over meadows of colored flowers and approaching a great golden city where her departed loved ones were waiting. She then remembered leaving her cane at the top of the mountain, which reminded her of her responsibility to her (living) loved ones. With this her superreal dream ended. The author felt she had an actual encounter with God and received divine guidance, and she herself identified her experience as a "greatly expanded Jungian archetypal dream."

If the assessment of this experience as an archetypal dream is correct, what is the implication for the near-death experience in which 
the same imagery, affects, and aftereffects are typically reported? The suggestion seems clear enough to me: both dream experience and NDE stem from the same matrix of consciousness and involve the same "mechanisms." At the very least it would seem that one theory must account for both sets of phenomena, "near-death dreams" and "classic" NDEs. This does not mean that NDEs are just dreams, mere fabrications of the personal unconscious, but it might mean that certain types of dreams and certain types of NDE proceed from the same collective psychic source.

\section{Mythology}

The world of myth is the world of collective dreams. As such we might expect to observe in it ample traces of the ADE. One very old example will serve us here. Australian aborigine myths of the afterlife contain many typical elements of modern NDEs. One tale (Robinson, 1969) described the person beginning the journey in darkness, sliding down "hollow grooves" in "a rocky, narrow gorge," entering flames (which scorched bad men), and then coming to clear spaces where the landscape was full of trees and free of undergrowth, and the grass especially green. There in the open space the spirittraveler was said to have met all his relatives and friends who had died before. They welcomed him and took him into the camp where he was dressed and painted, after which there was much shouting and play.

The basic motif of enclosure-disclosure, the passage from dark to light, from part to whole (symbolized by joining and playing with the ancestors), is present in this aboriginal myth. So too is the vertical polarity of the $A D E$, for we are told that if the spirit-traveler has been a "greedy and quarrelsome" fellow in life, he fails to reach the verdant camp of his ancestors. He is met by "an ugly old man" (Jungians will recognize this as the archetype of the Shadow) and crows who pick beakfuls of flesh from him and knock him about, leaving him scarred and disheveled forever.

That myth, the classical myths of heaven and hell, and the Tibetan teachings about peaceful and wrathful gods of the bardo or intermediate state bear out the bipolar nature of the ADE and suggest that the chthonic elements of NDEs are being repressed or concealed. Interestingly, references to anything like a pure being of light are absent in the aboriginal myths. This could mean that the idea of the individual Self has yet to emerge in the evolution of the human psyche. 
Mythology and the classics of world literature afford evidence of an archetype of death and enlightenment. ADE motifs run through the deepest structure of works such as the Epic of Gilgamesh, Dante's Divine Comedy, Plato's Allegory of the Cave, the Book of Revelation, Tolstoy's Death of Ivan Ilych, and so forth. We could say that such works are "classic" because they succeed in resonating with the great healing archetypes of the collective unconscious. Of course, myths and literary works are not purely spontaneous products of the unconscious; they are artifacts of culture and consciousness. Although even with the NDE or near-death dream, we have to distinguish between the original experience and the report of the experience. Nevertheless, detailed scrutiny of these phenomena will, I believe, disclose the common pattern I am labeling the ADE. The same remarks apply to the next three areas of comparison with the NDE.

\section{Mystery and Initiation Rituals}

Archaic rites of initiation are essentially ritual imitations of death and rebirth (Eliade, 1965a). They seek to accomplish in a group setting what Ramana accomplished on his own. The same can be said for the mystery rites of Greek and Roman antiquity. The Eleusinian Mysteries of ancient Greece will illustrate. The riddle of those august Mysteries, which lasted well over a thousand years, comes to this: what was the nature of the culminating ritual vision and what was the secret of its tremendous psychic efficacy? The effects themselves are clear from ancient testimonials. The most striking were a dramatic reduction of the fear of death, hope and belief in the reality of an afterlife, and a radiant transformation of the sense of this life.

Scholars long supposed that a special doctrine was revealed to initiates, persuading them there was a life after death. But Aristotle gave evidence that puts this out of court; he stated that during the rites, celebrants didn't learn anything but were "to be passive" and "to be put into a state" [pathein kai diatethenai]. The celebrant, in short, was put into an altered state of consciousness.

Three steps had to be taken in modern times to shed light on this ancient riddle. The first was psychedelic research. Albert Hofmann, who discovered LSD, argued that the kykeon, the ritual drink employed in the rites, was a potent psychedelic, chemically similar to LSD (Wassen, 1978). Drinking the kykeon after a nine-day fast would cause the "state" the initiates found themselves in. The second step concerned the archetypal content of the vision. According to Kerenyi 
(1967), the initiate experienced a beatific vision, radiant and ineffable, of the queen of the underworld: Persephone, daughter of Demeter, an archetypal expression of the source of life.

The third step was near-death research, which enabled us to understand the powerful aftereffects of the vision. It is no exaggeration to say that the Mysteries offered the euangelos, the good message of pagan antiquity, and like the Christian gospels that lit the overcast psyche of decadent antiquity, they endowed present existence with a new joy and pointed toward future existence with hope. Here are the words of a notable pagan initiate, Cicero: "We have been given a reason," he wrote in his treatise On the Laws, "not only to live in joy but to die with better hope" (neque solum cum laetitia vivendi rationem accepimus sed etiam cum spe meliore moriendi).

The poet Pindar declared: "Blessed (olbios) is he who, after beholding this (the epopteia or vision of the Mysteries), enters upon the way beneath the earth; he knows the end of life and its beginning given by Zeus" (Turyn, 1952, p. 335). It would be difficult to assert with confidence what this enigmatic statement signifies. Beholding the Mysteries enabled one to know the end (teleutan), the purpose, goal, or ultimate design of life, and at the same time the beginning (archan), the source, principle, or archetype of life. The fragment suggests that the epoptes, the seer or beholder, stepped outside the cycle of time, of beginning and ending, and gained an intuition of the underlying continuity behind and beyond the apparent transformations we call birth and death. Normally our perception of things is bound by just these limits: the beginning and the end. The Mysteries enabled one to see beyond these limits of ordinary perception, hence the bliss or blessedness of the aftereffect.

In a passage from an early Greek writer, Themistios (see Kerenyi, 1967), the connection between near-death and the Mysteries was specifically cited:

The soul [at the point of death] has the same experience as those who are being initiated into great mysteries ... [A]t first one is struck by a marvelous light, one is received into pure regions and meadows ... [ [and so forth].

For me it is hard to avoid the conclusion that much of the inner world of the ancient Mysteries and that of the modern near-death experiencer derives from a common source in the collective psyche of humankind. The ancient Greeks seem, in fact, to have worked out a fairly effective method for inducing a type of functionally equi- 
valent near-death experience. This, in my view, is the best hypothesis to account for the most striking effects of the rite: the reduction of the fear of death and the enhancement of the quality of life.

\section{Psychedelics}

Psychedelics have been used to induce initiation into the mysteries of death in the setting of modern psychotherapy (Pahnke, 1969; Grof and Halifax, 1977). According to Stanislav Grof and Joan Halifax, deep psychedelic experiences resemble the near-death experience in striking ways. Administered to the terminally ill or to the healthy individual, psychoactive substances like LSD facilitate ego death, both a symbolic and existentially quite real experience. Some common features of NDEs have been observed in drug-induced ego-death states, for instance, the life-review, and in the deepest stage of the experience, encounters with a variety of archetypal configurations.

Overall, however, the most striking similarity is the effect on the subject's concept of death. Again, the point deserves a full quotation:

Many individuals who had the experience of death and rebirth sometimes accompanied by feelings of cosmic unity independently reported that their attitudes toward dying and their concepts of death underwent dramatic changes. Fear of their own physiological demise diminished, they became open to the possibility of consciousness existing after clinical death, and tended to view the process of dying as an adventure in consciousness rather than the ultimate biological disaster. Those of us conducting this research kept witnessing, to our great surprise, a process that bore a striking similarity to mystical initiation ... (1977, p. 20).

The authors noted parallels in the phenomenology of rites of passage and the perinatal (death-rebirth) phase of the LSD experience. They also made the point that eschatological mythologies should be taken as maps representing unusual psychic states and processes. All these parallels and representations display the outline of a continuum of death-related experiences. Rites of transformation, spontaneous mystical experiences, psychedelic amplifications of consciousness, near-death episodes, and other states seem to overlap in their objective circumstances and internal effects. My thesis is that there is a collective, worldwide and world-old, psychic mechanism operating behind this great family of spiritual manifestations. Nature, given these persistent psychic automatisms, is evidently trying to say something to us. The message, stripped to essentials, concerns the inde- 
structability of life. The god is dismembered, yet he is resurrected. The darkness is followed by unspeakable illumination. Escape is possible from the cave of being. And so on. The message speaks to us in many ways; moreover, unless we are too arrogant to admit it, we need to listen. By bringing into focus the reality of the archetype of death and enlightenment, the near-death experience is sensitizing our ears, helping us to listen more attentively.

Despite the continuum, however, it would be a serious mistake to ignore important differences. The modern psychedelic therapist works with individuals, and with minor exceptions allows the demons and angels of the deep unconscious to surface in a relatively haphazard fashion. The ancient therapist or hierophant worked under more controlled circumstances. First, there was a group setting and a generally broad social sanction. There were a common myth, a common belief-system, and target symbols around which psychic energies more easily constellated. Participants were programmed through ritual ablutions, fasting, psychodramas, and sacrificial behaviors, all designed to facilitate and rationalize the annihilation of ego consciousness. Unfortunately, the modern medical paradigm does not favor the more holistic approach of the ancients. Modern science has broken asunder what the archetypal vision keeps whole.

The most obvious example is the sundering of death from life. The dominant medical paradigm sees death as terminal, the opposite, the negation of life. The archetypal vision sees the relationship as dialectical. Living is inseparable from dying. That is why we can and should explore our dying not suddenly, without preparation, at "terminal" junctions, but as a ritual component of our living existence. The archetypal paradigm declares the healing venture to be an ongoing process of everyday life. The horrible neglect of the quality of everyday life is a disease we have no doctors for. The research into psychedelics, mythology, comparative religion, and other disciplines indicates the acute need for a more radically organic approach to the concept of healing and wholeness, of what it means to become a Self. Near-death research may occupy a strategic role in this all-important new synthesis. It demonstrates a latent potential of consciousness that deserves to be liberated for the whole of life, not only at the end of it.

\section{UFO "Revelations"}

Compared with ancient and primitive societies, modern scientific culture provides few inlets for the healing powers of the collective 
unconscious. To be sure, these powers appear spontaneously to individuals in dreams and in near-death states. If Jung was right, we are, in this age of science, projecting the archetypes into the skies in the form of Unidentified Flying Objects (UFOs). The possible physical realities behind these appearances in the sky are not the issue here but their psychological content.

According to Jung, UFO phenomena are signs of the end of the era. "Apparently," he wrote, "they are changes in the constellation of psychic dominants, of the archetypes, or 'gods' as they used to be called, which bring about, or accompany, long-lasting transformations of the collective psyche" (1964, p. 311). These sky epiphanies may, in short, be thought of as the psychic products of the near-death experience of modern civilization.

The epilogue to Jung's book on flying saucers dealt with the case of Orfeo Angelucci, a "contactee" who had a close encounter resulting in a conversion experience. Based on Jung's account, I was able to find almost every element in the prototypical NDE, along with the rarer phenomena such as transcendental music. In brief, Orfeo had a succession of experiences in which he "saw" various lights, apparitions of men and women alleged to be friends from another world. Voices were heard but communications were said to be directly mental. Orfeo felt himself on the verge of death but also that he had transcended mortality. He found himself aboard a UFO that carried him away, beheld a white flash of lightning, saw his whole life laid out before him, received teachings, had a vision of knowledge, was carried to heaven where he observed transcendental landscapes and heard transcendental music, and so forth. All the motifs of the NDE are present, jumbled and dressed in space-age imagery. The experience produced powerful metanoid effects along with plenty of ego inflation.

The imagery and effects here are structurally and psychologically analagous to the typical NDE. It would appear that the NDE and some UFO experiences stem from a common source in the collective unconscious. The Australian aborigine adapts the motifs differently from Orfeo, the twentieth-century mechanic, but, allowing for cultural inflections, we seem to be observing a primordial structure of the human psyche.

\section{SOME POSSIBLE OBJECTIONS TO THE THEORY}

Before I make some concluding remarks, several possible objections to the present theory should be addressed. The first is that 
there might at first appear to be no way to falsify the theory. The theory of archetypes - in principle like any theory - can be stretched ad hoc to embrace discrepant phenomena. But there is a special difficulty in identifying an archetype as such. There is no unequivocal mark by means of which we can say that some particular psychic presentation is definitely archetypal. Nevertheless, there are identifying features of archetypes - their universality, numinosity, horizontal and vertical bipolarity, etc. - that one can appeal to. Once these features are specifiable, failure to identify some or all of them in NDEs would be one way to falsify the theory. As the archetypal approach is refined, more precise assertions and predictions will become possible, thus rendering it more precisely falsifiable.

Another type of objection might be that the NDE is explainable by physiological mechanisms such as endorphins, etc. But even if convincing correlations between brain mechanisms and NDEs were established - and this is by no means the case yet - we would not necessarily have a complete explanation. The meaning of the NDE, the psychological significance of the typical imagery, and the affects and aftereffects in relation to the imagery still need to be explained.

Only the most simplistic reductionist would be content to say these experiences consist in nothing but their possible brain-state correlates. On the other hand, we would expect certain brain changes to occur in conjunction with the dying process. Dying, after all, is both a psychological and a biological process. The description of those brain changes would then be part of the total explanation of the NDE.

For example, it has been suggested (Lindley, Bryan, and Conley, 1981) that stress-induced increases of endogenous opiates are causally related to the peace and well-being experienced during the near-death experience. There is nothing in the theory of archetypes at odds with such partial neurophysiological explanations. Jung believed that the archetypes were deeply connected with biological functioning. He never tired of comparing them with the specific organ systems of normal physiology. There is a physiology of the psyche, and the archetypes are among the organs of the psychic system. In his later writings Jung spoke of the archetypes as psychoid, as peculiar intermediary structures bridging the gap between nature and psyche. This, incidentally, would explain why certain archetypes might symbolically foreshadow the discovery of the laws of external nature.

The NDE is a complex family of phenomena. For instance, it appears that there are several gradations of peace, ranging from painless euphoria to intense elation. These emotions appear to have 
various links to the NDE, in relation to the tunnel or dark phase of the experience, to the out-of-body experience, to the meeting with light-beings, otherworldly messengers, and landscapes, etc. Some positive affects may be due to endorphins, others to the out-of-body process, still others to the experience of archetypal ideas. We may find that each causal strand has its function and its sphere of operation.

Aspects of the visual imagery - the whorl or tunnel pattern, for instance - may also be based upon neurophysiological mechanisms. Kluver (1969) found certain form constants (including, typically, the "tunnel," "funnel," "cone," etc.) resulting from mescaline intoxication. But, as Kluver observed, the common, initial geometric patterns are points of departure for later psychological elaborations of imagery. The neurophysiological factor would not explain the whole development of the near-death imagery. The causal ancestry of a motif might lie in brain physiology and the archetypal sources.

Consider, for example, the near-death tunnel-motif that Kluver also observed in mescaline intoxication. This particular geometric pattern and its variants - cone, whorl, funnel, etc. - lend themselves to formation of circular, or mandalalike, patterns. But the mandala an image expressive of centralizing tendencies - is a symbol of the archetype of the Self. In the context of the near-death experience, then, the neuro-based pattern would acquire an important symbolic function, signaling that the ego was about to encounter the Self.

A third problem is with the paranormal. The theory of archetypes does not directly explain the psi phenomena associated with NDEs. This is a valid but not a fatal objection. In the first place, the theory of archetypes is compatible with psi phenomena in a way that less open-ended systems of psychology such as behaviorism and psychoanalysis are not. Further, archetypes themselves, strictly speaking, are paranormal phenomena, since they are types of mental presentation for which there is no normal physical explanation.

One further objection might seem the most damaging. The archetypes are by definition universal psychic structures. But in many NDEs and deathbed visions there are specific and individual elements such as "seeing" particular deceased relatives. Isn't the theory at odds with these elements of specificity and individuality?

It would seem not. As Jung observed, there is no sharp dividing line between the personal and the collective unconscious. Thus, dreams with collective material are mingled with items from the personal unconscious. Or else archetypal contents might mingle with individual aspects of waking experience through the mechanism of 
projection. For instance, a man may project his Anima (feminine archetype) upon a particular woman, or the Shadow (his disowned negativities) upon a casual stranger. This shows that so-called archetypes are not entities that exist in some detached and self-enclosed sphere but rather designate special modes of highly individuated experience.

Mixtures of collective and individual elements often appear in the near-death experience. In the same NDE or deathbed vision we find reports of light-beings - religious figures such as angels, Christ, or the Buddha - along with particular deceased relatives. In addition, the particular deceased relatives often appear in a transfigured, idealized, hence more archetypal form. We cannot then say that the theory of archetypes fails to do justice to the unique and specific features of near-death experiences.

Finally, there are two further problems that arose in a paper by Glen Gabbard and Stuart Twemlow (1981). Gabbard and Twemlow considered the Jungian approach reductionistic and redundant in the logical sense of being a tautology. They also raised doubts about the explanatory power of the theory of archetypes. These are important problems, which I will now address in detail.

Reductionism. In a previous paper cited by the authors (Grosso, 1981 ), I criticized certain accounts of NDEs as being reductionistic. The specific sense of "reductionistic" I used was perfectly clear from the context. So, for instance, I said that "the difficulty arises in seeing the NDE as nothing but an illusory psychophysiological reflex" (p. 53). We could say that in one sense a "reductionistic" theory is any theory that automatically implies the negation of the "transcendental" claims of the NDErs.

Actually, there are two correct senses of "reductionism." One sense is pejorative and is the subject of Arthur Koestler's anthology Beyond Reductionism (1969). The last presentation in the anthology, by Victor Frankl, "Nihilism and Reductionism," is the strongest statement along these lines. For Frankl reductionism is virtually equivalent to dehumanization. We observe this virulent form of reductionism in theories that see in human behavior nothing but (for example) the economic, the sexual, or the mechanist principles at work. There reductionism is a leveler and destroyer of human meanings, a crude simplifier. An example would be a psychoanalyst reducing the cult of the Virgin Mary to the oedipal complex or incest fantasies.

Now although Gabbard and Twemlow condemned Ronald Siegel (1980) and Jan Ehrenwald (1974) as reductionistic in this pejorative 
sense, they showed themselves to be reductionistic in the same pejorative sense in the very first sentence of their paper: "The recent, enormous popularity associated with near-death experiences ... . is very likely related to the fantasy that the near-death experience may offer a glimpse of a possible life after death" (1981, p. 68) (italics added). The authors automatically classified the NDE as a fantasy, which is exactly what Siegel has argued. Why then are Gabbard and Twemlow any less reductionistic than Siegel? The only difference is that Siegel argued his case while Gabbard and Twemlow merely assumed the NDE is a fantasy. But this is consistent with the latter's penchant for treating other writers as if they were patients, as when they wrote:

The researcher's narcissistically invested theory is perceived to be perfect and capable of providing ultimate answers to complex and seemingly unexplainable phenomena. In this sense, such a theory attenuates the scientist's sense of vulnerability and helplessness in the face of puzzling and inscrutable data, data that may shake the very foundation of one's belief system. Nowhere are irrational and narcissistic factors more likely to impinge on the researcher's objectivity than in the investigation of what happens to us when we die, for this is not a dispassionate issue (1981, p. 69) (italics added).

But this is to argue ad hominem; moreover, are we to assume that Gabbard and Twemlow escape the stigma of narcissistic fondness for their own views on NDEs? The fact is that one might be narcissistically invested in one's theory and be quite on mark, or one might be nonnarcissistically invested in a theory and be grossly wide of the mark.

In any case, it is absurd to call the Jungian approach to NDEs reductionistic in the pejorative sense. The Jungian view respects the inner validity and objectivity of transpersonal psychic contents; it is sympathetic and encouraging to the near-death experiencer's sense of meaningfulness; and it is open to the possibility of postmortem existence. One would have to be "narcissistically invested" in a rival theory not to see that this is the case with the Jungian approach.

The second sense of reductionistic, however, is another matter. In this sense all explanations are in some (nonpejorative) sense reductionistic. That is, phenomena being explained are "reduced" to their explanatory principles. The falling apple is explained, that is, reduced to the law of gravity. To describe the Jungian perspective as "reductionistic" in this sense is both true and trivial. 
The explanatory power of archetypes. This brings me to the second problem raised by the Gabbard and Twemlow paper. Their basic contention was that to try to explain NDEs by archetypes is a tautology. Gabbard and Twemlow did not argue their case; they just dogmatically denied that the Jungian concepts have any explanatory value. Is talk of archetypes a tautologous relabeling of NDEs? This would be like calling a bachelor an unmarried man. It wouldn't be very illuminating to try explaining why Jones was a bachelor by saying he was an unmarried man. But it's ridiculous to say that this is what is happening when one tries to explain NDEs by archetypes. Archetype is not a variant expression identical in meaning with $N D E$; the latter is a descriptive label, the former a theoretical term that refers us to a complex conceptual apparatus. Of course, this fact by itself does not guarantee that archetypes are useful explanations of NDEs, though the present paper is an attempt to show that they are. The point here is that we cannot dismiss the archetypal account simply on grounds that it is a tautology. There is nothing tautologous in claiming that NDEs are products of the transpersonal unconscious; the claim may be false but it is not logically redundant.

The problem of what is an explanation, scientific or otherwise, is very complicated. There are different kinds of explanation and different levels of completeness in explanation. Moreover, an arbitrary element enters into what we count as a satisfactory explanation. For instance, one person may think diabolic illusion is the best explanation of NDEs, but this would be a dead end for someone who took no stock in the devil's existence. The explanatory power of archetypes - or any model or theory - is not in itself a fixed quantity. Everything depends upon future development. It is up to researchers to make the most of models or theories, to test them for consistency, for comprehensiveness, and for their ability to generate fresh experimental hypotheses. Explanatory power is an interactive variable; paradigms in science are consensual forms in pursuit of truth. To the degree that NDEs are genuinely anomalous, they call for a new paradigm. But a new paradigm demands the growth of a new consensus. At this point we need to stress the valid links in the field, the points of convergence. For this reason I have sought to forge links between the Jungian and parapsychological perspectives, without which we may fail to do justice to the transpersonal character of the near-death experience. We need, in short, a transpersonal conceptual grid to do justice to the unique pattern of human experience we are trying to explain. 


\section{THE ONTOLOGICAL QUESTION}

Let us suppose that indeed the NDE is one peak that is part of a mountain range, a transpersonal psychic structure linked to death and the process of enlightenment. This mountain range represents the high points of the human spirit. St. Paul, Socrates, Ramana, and countless others have scaled this region of consciousness. It has inspired great philosophers, prophets, and mystics and has been the source of age-old rituals of renewal, and of visions and dreams that define and sustain the forms of spiritual life.

Let us further assume that these spiritual forms, including the NDE, derive from the same psychic matrix. This poses a challenging question. If we declare that NDEs are nothing but hallucinations, spasms of epileptic brains, epiphenomena of peptides, or projections of delusions and death-anxiety, then the same would apply to the rest of the mountain range. The NDE and the spiritual traditions of humankind stand or fall together.

This way of putting it may seem overstated to some, no doubt. Yet a question remains that haunts at least some of us. Is this mountain range a gigantic hoax, perhaps a vital lie or healing phantom but at bottom a projection without substance? Is this mountain range of the human spirit the real Maya - the playful illusion of the great deniers of death? This is an uncomfortable question to ask. Yet the truth claims, not only concerning NDEs but concerning the great spiritual traditions, need to be faced head on. We cannot mark time forever in the twilight regions of phenomenology. The question was posed by Charles Tart (1979). Of course, transpersonal experience is "real" - as experience. But so are the projections of psychotics and the daydreams of schoolchildren.

Those who speak to us from the mountain range talk of transcending time and space. Is this merely metaphoric or physically true? The arguments of philosophy are inconclusive on this question. However, parapsychology, in addressing such space-time-transcending capabilities, is crucial in the ontological debate. Take away the paranormal, and the realm of spirit is reduced to glorious metaphor therapeutic perhaps but at bottom delusive. Add the paranormal and the picture changes considerably. Talk of spirit then acquires a fresh ontological energy.

But we have yet to broach the question of life after death. Surely the popular interest in the NDE revolves around the promise of survival. The experiencer loses the fear of death because he or she is convinced that there is life after death, that at death he or she is 
going on an interesting trip somewhere, not nowhere. Further, the therapeutic value of the NDE is based on the patient's new belief. He or she believes - even claims to know - that this transcendental world that has been glimpsed is really real. The medical value of the NDE is logically linked to this belief, and beliefs can be true or false. From the medical and from the spiritual viewpoints, there is the same problem of truth claims and the same possible use of parapsychology in helping to resolve them.

This brings us to the prediction that the theory invites us to make. It was already noted how the archetypes, being in part images of cosmic forces, analogues linking the structure of psyche and nature, may sometimes foreshadow scientific discoveries. How this works is a problem that deserves detailed attention, but for now a few examples will have to suffice. For instance, Jung (1968) cited the archaic idea of the sun-wheel as a forerunner to the invention of the wheel. Alchemy, full of archetypal ideas, was the forerunner of modern chemistry, Alchemy, according to Jung, also anticipated developments in modern depth psychology. The physicist Wolfgang Pauli (1955) wrote of the influence of archetypal ideas on Kepler's scientific discoveries.

If this relationship between the transpersonal psyche and nature exists, we are entitled to ask what, if anything, the archetype of death and enlightenment foreshadows? What are these extraordinary images telling us about our place in nature? What hints do they give about what we have yet to discover and yet to demonstrate by means of our modern scientific intelligence?

The most persistent idea of the ADE is the association of light an obvious symbol of consciousness - with death. The harbingers from the deep unconscious repeat in many forms the same message: death is the gateway to renewed and possibly enlarged being, not extinction but greater consciousness.

But what does all this mean in terms of scientific prediction? There is only one scientific discipline concerned with life after death: parapsychology, both directly and indirectly, has been grappling with this problem for a hundred years. The ADE may therefore be said to foreshadow the parapsychological confirmation of life after death. Needless to say, there is no crucial experiment we can devise to test this prediction; moreover, research in this area is riddled with methodological difficulties. Nevertheless, the theory points unequivocally toward survival.

So far, however, near-death research has not addressed the survival question. Near-death data have been treated phenomenologically or 
statistically analyzed for their relation to different variables. But researchers have not looked at data specifically with the survival hypothesis in mind. Moody (1975) and Ring (1980) were therefore right in denying that their work supported the survival hypothesis. Only Sabom's (1982) work, which attempted to verify the out-ofbody component in NDEs, began to address the survival question.

The work on deathbed visions (Barrett, 1926; Bozzano, 1906; Osis and Haraldsson, 1977) has addressed the survival problem. Results from this and other types of survival research, though not conclusive, strongly clash with the Freudian outlook, for which the unconscious is a source of deception in regard to survival. For Jung, however, the deep unconscious contained genuine intimations of immortality. My conclusion then is that the NDE, viewed from a Jungian perspective, encourages us to entertain the hypothesis common to the beliefs of the collective human psyche but rejected by modern science - that the death of the body holds the promise of the continuation, even the expansion, of human consciousness.

\section{NOTE}

1. My comments on these two dreams are restricted to the overt near-death-related motifs. The full, personal significance of the dreams is another matter. As Jung always stressed, dreams are best understood in series and with the help of the personal associations of the dreamer.

\section{REFERENCES}

Arbman, E. Ecstasy or Religious Trance, Vol. II. Stockholm: Scandinavian University Books, 1968.

Atwater, P.M.H. Coming back. Vital Signs, 1981, 1(3), 6.

Audette, J. Visions of knowledge in NDEs. Vital Signs, 1982, 1(4), 5-6.

Barrett, W.F. Death-Bed Visions. London: Methuen, 1926.

Becker, C. The centrality of near-death experiences in Chinese Pure Land Buddhism. Anabiosis, 1981, 1, 154-171.

Bozzano, E. Apparitions of deceased persons at death-beds. Annals of Psychical Science, 1906, 5, 67-100.

Edinger, E. Ego and Archetype. Baltimore: Penguin Books, 1974. Ehrenwald, J. Out-of-the-body experiences and the denial of death. Journal of Nervous and Mental Disease, 1974, 159, 227-233. 
Eliade, M. Rites and Symbols of Initiation. New York: Harper and Row, 1965a.

Eliade, M. Shamanism. New York: Pantheon Books, 1958.

Eliade, M. The Two and the One. New York: Harper Torch Books, $1965 b$.

Flynn, C. Meanings and implications of NDEr transformations. Anabiosis, 1982, 2, 3-14.

Gabbard, G.O., and Twemlow, S.W. Explanatory hypotheses for near-death experiences. Re-Vision, 1981, 4(2), 68-71.

Gabbard, G.O., Twemlow, S.W., and Jones, F.C. Do "near-death experiences" occur only near death? Journal of Nervous and Mental Disease, 1981, 169, 374-377.

Greyson, B. Organic brain dysfunction and near-death experiences. Presented at the American Psychiatric Association 135th Annual Meeting, Toronto, 1982.

Greyson, B. Toward a psychological explanation of near-death experiences. Anabiosis, 1981, 1, 88-103.

Grof, S., and Halifax, J. The Human Encounter with Death. New York: E.P. Dutton, 1977.

Grosso, M. The cult of Dionysos and the origins of belief in life after death. Parapsychology Review, 1981a, 12(3), 5-8.

Grosso, M. Death and the Myth of the True Earth in Plato's Phaedo. Columbia University Ph.D. Thesis. Ann Arbor, Mich.: University Microfilms, 1971.

Grosso, M. Toward an explanation of near-death phenomena. Anabiosis, 1981b, 1, 3-26.

Jacobi, J. Complex, Archetype, Symbol in the Psychology of C.G. Jung. Princeton, N.J.: Princeton University Press, 1974.

Jung, C.G. Aion. Princeton, N.J.: Princeton University Press, 1959. Jung, C.G. Analytical Psychology: Its Theory and Practice. New York: Pantheon Books, 1968.

Jung, C.G. The Archetypes and the Collective Unconscious. Princeton, N.J.: Princeton University Press, 1971.

Jung, C.G. Civilization in Transition. Princeton, N.J.: Princeton University Press, 1964.

Jung, C.G. Memories, Dreams, Reflections. New York: Random House, 1961.

Jung, C.G. Psychological commentary. In W.Y. Evans-Wentz (Ed.), The Tibetan Book of the Dead. London: Oxford University Press, 1957.

Jung, C.G. Psychology and Religion: West and East. London: Routledge and Kegan Paul, 1958. 
Jung, C.G. The Structure and Dynamics of the Psyche. Princeton, N.J.: Princeton University Press, 1978.

Jung, C.G. The Symbolic Life. Princeton, N.J.: Princeton University Press, 1976.

Kerenyi, C. Eleusis: Archetypal Image of Mother and Daughter. New York: Pantheon Books, 1967.

Kluver, H. Mescal and Mechanisms of Hallucinations. Chicago: University of Chicago Press, 1969.

Koestler, A. (Ed.). Beyond Reductionism. Boston: Beacon, 1969. Lindley, J., Bryan, S., and Conley, B. Near-death experiences in a Pacific Northwest American population. Anabiosis, 1981, 1, 104-124.

Moody, R.A. Life After Life. Atlanta: Mockingbird Books, 1975. Noyes, R. Dying and mystical consciousness. Journal of Thanatology, 1971, 1, 25-41.

Noyes, R., and Kletti, R. Depersonalization in the face of lifethreatening danger: a description. Psychiatry, 1976, 39, 19-27. Osborn, A. Ramana Maharshi and the Path of Self-Knowledge. New York: Weiser, 1973.

Osis, K., and Haraldsson, E. At the Hour of Death. New York: Avon Books, 1977.

Pahnke, W. The psychedelic mystical experience in the human encounter with death. Harvard Theological Review, 1969, 62, 1-21.

Pauli, W. The influence of archetypal ideas on the scientific theories of Kepler. In C.G. Jung and W. Pauli, The Interpretation of Nature and the Psyche. London: Routledge and Kegan Paul, 1955.

Rawlings, M. Beyond Death's Door. New York: Thomas Nelson, 1978.

Ring, K. Life at Death. New York: Coward, McCann and Geoghegan, 1980.

Ring, K. Precognitive and prophetic visions in near-death experiences. Anabiosis, 1982, 2, 47-74.

Robinson, R. Aboriginal Myths and Legends. New York: Hamlyn Publishing Group, 1969.

Sabom, M. Recollections of Death. New York: Harper and Row, 1982.

Siegel, R. The psychology of life after death. American Psychologist, 1980, 35, 911-931.

Skaar, M. My personal encounters with death. Vital Signs, 1982, $2(1), 14-15$. 
Tart, C. Transpersonal experience: realities or neurophysiological illusions? Journal of Indian Psychology, 1979, 2, 93-113.

Turyn, A. (Ed.). Pindari Carmina cum Fragmentis. Cambridge, Mass.: Harvard University Press, 1952.

Wassen, G. The Road to Eleusis. New York: Harcourt Brace Jovanovich, 1978.

Requests for reprints to:

Michael Grosso

1422 River Road

Edgewater, New Jersey 07020 